\title{
PHYSIOTHERAPY IN PATIENTS W ITH CHRONIC RESPIRATORY FAILURE IN CLINICAL STAGE
}

\author{
Milena Nikolova ${ }^{1}$, Nikolay Izov $^{1}$, Ivan Maznev ${ }^{1}$, Ivan Ivanov ${ }^{1}$, \\ Danche Vasileva ${ }^{2}$, Antoaneta Dimitrova ${ }^{1}, K_{\text {ristin Grigorova-Petrova }}{ }^{1}$
}

\author{
${ }^{1}$ National Sports Academy "Vassil Levski", Sofia, Bulgaria \\ ${ }^{2}$ Faculty of Medical Sciences, Goce Delchev University, \\ Shtip, Republic of Macedonia
}

\begin{abstract}
AIM: To evaluate the effect of physiotherapeutic (PT) methodology including inspiratory training device on functional status in patients with acute exacerbation of chronic obstructive pulmonary disease (COPD) and chronic respiratory failure (CRF) in clinical stage.

METHODS: 20 patients with exacerbation of COPD in clinical stage divided into experimental group (EG) and control (CG) were examined. One week in-hospital physical therapy sessions were conducted. All patients were applied the same PT methodology, but in the EG in addition was included individual inspiratory training device without resistance of inhaled air. For the purpose of the study are double-tracked and evaluated the following tests and measures: breathing rate at rest, saturation and two apneic tests.

RESULTS: After completion of the PT sessions there is an increase in saturation, in the strength of intercostal muscles and diaphragm according the tests for inspiratory and expiratory apnea and decrease in the respiratory rate at rest in both groups, but in the EG the results were better in mean values.

CONCLUSIONS: The use of inspiratory training device without resistance in patients with COPD and CRF in a period of exacerbation in clinical stage leads to significant positive effect on studied parameters.
\end{abstract}

Key words: COPD; inspiratory training device; physiotherapy

\section{Introduction}

Chronic obstructive pulmonary disease (COPD), is a group of respiratory diseases, including pulmonary emphysema and chronic obstructive bronchitis, which almost always present together in varying degrees of manifestation with progressive development of chronic respiratory failure (CRF).

COPD is considered to be a major global epidemic, as one in ten adults over 40 years most likely has COPD. Almost 3 milion people worldwide have died from COPD annually. According to the World Health Organization, COPD is the sixth leading cause of death in the world. The prediction is that by 2020 COPD is going to be the third leading cause of death worldwide after the heart attack and stroke (Kostov, 2004).

Pulmonary rehabilitation is integrated into the over- all approach of treating patients and it is individually aimed at reducing the burden of respiratory complaints, optimizing the functional status, keeping patients in a stable condition, preventing the complications of other organs and systems, and reducing the economic expenses and the need for health care. Moreover, it is the most effective therapeutic strategy for reducing breathlessness, improving the physical endurance, and improving the quality of life compared to the standard and self- medication treatment (Kostov, 2004; Karaneshev, 1991).

The physiotherapy is the most important part of a complex pulmonary rehabilitation. It positively affects patients with COPD and CRF at all stages of the disease (Berry et al., 1999), and the long-term effect of a PT course of treatment is undoubtedly proven (Foglio et al., 1999; Griffiths et al., 2000; Young et al., 1999). One of the most common causes of pro- 
gressive worsening of pulmonary function and the progressive development of a chronic respiratory failure is Chronic Obstructive Pulmonary Disease.

Chronic respiratory failure is a disease state in which the exchange of oxygen and carbon dioxide between the atmosphere and the blood in the lungs is impaired, and the normal oxygen content (hypoxemia), and later the carbon dioxide in the arterial blood (hypercapnia), can not be supported. CRF occurs in a number of acute and chronic diseases of the cardiorespiratory system, blood diseases, some diseases of the central nervous system and others. The most progressive chronic bronchopulmonary diseases cause respiratory failure, which is often accompanied by a cardiovascular failure and neuropsychiatric syndrome. Depending on the nature of the underlying disease process, respiratory failure occurs acutely or chronically. Chronic pulmonary failure develops progressively over most chronic diffuse bronchopulmonary diseases, most commonly due to the chronic bronchitis, bronchial asthma, and pulmonary emphysema. All other diffuse diseases of the lungs and thorax could also cause respiratory failure (Dimitrova, 2009).

Targeted respiratory rehabilitation is recommended for all patients, especially if they have reduced physical tolerance, dyspnea on exertion, fatigue, and/or impaired daily motor activity. The early administration of PT in COPD patients has demonstrated clinically significant improvements in the quality of life and health status (Dimitrova, 2013).

Weakness of the respiratory muscles in the majority of COPD patients, even in the early stages of the diseases, is observed and it leads to the appearance of hypercapnia, dyspnea, night oxygen desaturation, and reduced functional walking options. It is proven that during physical exercises, diaphragm work increases in COPD patients as compared to healthy individuals, and causes quicker respiratory muscle fatigue and shortness of breath.

Inspiratory muscle training (IMT), in addition to the selected physiotherapeutic methodology, is suitable for use in a number of respiratory illnesses, but studies on its influence on the functional status of patients with COPD at the clinical stage are quite controversial. Some researchers conclude that IMT increases the muscle strength and endurance of the respiratory muscles and reduces the dyspnea. Other authors believe that adding of IMT to the general training program does not significantly improve the physical capacity and quality of life of the patients. The exact characteristics of the patients with COPD, which require the inclusion of IMT with devices as part of the therapeutic exercises in PT sessions, have not yet been established (Gosselink, 2011).

This study aimed to research the effect of the use of an inspiratory training device without resistance on the functional status of patients with CRF due to exacerbation of COPD.

\section{Material and methods}

Twenty patients with exacerbation of COPD and CRF in the St. Anna University Hospital - Sofia, were examined. The study covers the period from the hospitalization of patients and administration of physiotherapy to their discharge from the pulmonary disease clinic (an average of 7 days). The contingent was divided into two groups - control (CG) and experimental (EG) (Table 1). The EG consisted of 10 patients selected according to their desire to perform an inspiratory training with an individual Coach2 Incentive Spirometer without resistance, in addition to the individual PT procedures. The CG included 10 patients who were treated with the same PT methodology as the EG but without an inspiratory training device. The patients were in the second stage of COPD according to GOLD (Global Initiave for Chronic Obstructive Pulmonary Disease, 2014) with a mean disease duration over 10 years.

For the purposes of the study, the following indicators were tracked and evaluated: respiratory rate at rest (number of inspirations/min.), oxygen saturation at rest (\%), inspiratory and expiratory apnea tests (sec.).

The PT complex comprised the following administered to patients in both groups: nasal, thoracic and diaphragmatic breathing; rhythmic exercises for distal muscle groups; resistance exercises against upper limbs; specific breathing techniques; relaxing massage of the intercostal muscles; active exercises including slopes and curves; exercise to stimulate expectoration and coughing, and dosed walking.

The patients from the EG performed an inspirational muscle training with an individual Feedback Device Coach 2 Incentive Spirometer without inspi- 
ratory resistance. All patients in the experimental group, after the initial tests, were given inspiratory exercise devices and precise and clear instructions, in order to allow them to practice 3-4 times a day for self-training. According to the norm, depending on the height, gender and age of the patients, the maximum amount of air was set to be inhaled slowly and gradually. The inspiration itself was through the mouthpiece which is linked to the section that shows how steady the breathing is, and in turn is related to the section indicating the amount of inhaled air. Each series consisted of 3-4 inspirations and after each inhalation a rest of $30 \mathrm{sec}$. was made. The inhalation time duration must be at least 3 sec. 3-4 series of inspirations were performed throughout the duration of the whole day. The use of this device, provided with a scale allowing visual control of the velocity and volume of the breathed air, stimulated a slow and deep inhalation. The aim was to improve the strength and endurance of the inspiratory muscles.

In the clinical stage of treatment, the load was determined by the patient's current status. The functional capabilities of patients and their clinical conditions were taken into consideration, and the load was optimal and distributed twice a day.

Student's t-criterion was used to determine the change significance for each group in the course of treatment, and the significance of the changes between the two groups.

\section{Results and discussion}

The general characteristic of the surveyed contingent is presented on table 1 .

Table 1. Common characteristic of the contingent

\begin{tabular}{|c|c|c|c|}
\hline \multicolumn{2}{|c|}{ Parameter } & EG & CG \\
\hline \multicolumn{2}{|c|}{ Mean age } & $59,5 \pm 8,9$ & $67,8 \pm 3,8$ \\
\hline \multicolumn{2}{|c|}{ 41-50 years } & 0 & 1 \\
\hline \multicolumn{2}{|c|}{ 51-60 years } & 2 & 4 \\
\hline \multicolumn{2}{|c|}{ 61-70 years } & 6 & 5 \\
\hline \multicolumn{2}{|c|}{$71-80$ years } & 2 & 0 \\
\hline \multirow{2}{*}{ Gender } & male & 4 & 5 \\
\hline & female & 6 & 5 \\
\hline \multicolumn{2}{|c|}{ Smoking status } & 5 & 2 \\
\hline
\end{tabular}

EG - experimental group; $C G$ - control group

The results of monitored saturation, respiratory frequency at rest, and functional breathing tests, objectively reflect the changes in the cardiorespiratory system in both groups of patients, and are presented on table 2.

Table 2. Changes of the respiratory parameters and the saturation (mean value and standard deviation) in the experimental and control groups before and after treatment

\begin{tabular}{|c|c|c|c|c|}
\hline Parameter & Group & mean value $\pm S D$ & mean value \pm SD & Difference $\left(X_{2}-X_{1}\right)$ \\
\hline \multirow{3}{*}{$\begin{array}{l}\text { Respiratory rate at rest } \\
\text { (number of breaths/min) }\end{array}$} & EG & $23.5 \pm 2.6$ & $20.8 \pm 1.8^{\star \star}$ & -2.7 \\
\hline & CG & $24.0 \pm 0.8$ & $21.4 \pm 0.5^{\star * *}$ & -2.6 \\
\hline & $\mathrm{P}$ & 0.605 & 0.350 & \\
\hline \multirow{3}{*}{ Saturation at rest (\%) } & EG & $91.6 \pm 6.0$ & $94.5 \pm 5.8^{\star *}$ & 2.9 \\
\hline & CG & $81.9 \pm 7.1$ & $77.39 \pm 8.60^{* *}$ & 5,1 \\
\hline & $\mathrm{P}$ & 0.010 & 0.010 & \\
\hline \multirow{3}{*}{ Inspiratory apnea (sec) } & EG & $18.4 \pm 6.2$ & $21.5 \pm 5.4^{* * *}$ & 3.1 \\
\hline & CG & $19.0 \pm 1.9$ & $20.9 \pm 1.8^{\star * *}$ & 1.9 \\
\hline & $\mathrm{P}$ & 0.788 & 0.761 & \\
\hline \multirow{3}{*}{ Expiratory apnea (sec) } & EG & $15.9 \pm 4.7$ & $18.9 \pm 3.6^{* * *}$ & 3.0 \\
\hline & CG & $16.0 \pm 1.4$ & $77.39 \pm 8.60^{* * *}$ & 2.1 \\
\hline & $\mathrm{P}$ & 0.944 & 0.579 & \\
\hline
\end{tabular}

The two apneic tests reflect the condition of the cardiorespiratory system. There are no fixed norms for the parameters of inspiratory and expiratory apnea in elderly people.
As it is known, the expiratory apnea test provides indirect information about the left atrial and left ventricular functional conditions, and the inspiratory apnea test provides indirect information about 
the right heart half. The inspiration increases intrathoracic pressure, which prevents blood movement from the right ventricle to the lungs. In healthy middle-aged individuals, the breathing retention time after inspiration usually is an average of $40-50 \mathrm{sec}$., and the breathing retention time after expiration is $30 \mathrm{sec}$. on average. An inspiratory test under $15 \mathrm{sec}$. and expiratory test under $10 \mathrm{sec}$. is considered to be a sign of impaired cardiac and pulmonary function (Slŭnchev, Toteva, 1975; Slŭnchev at al., 1986).

The results of the two apneic tests from the patients in the EG, before the applied PT, were on average $18.4 \mathrm{sec}$. for the inspiratory apnea and on average of $15.9 \mathrm{sec}$. for expiratory apnea. This indicates worsening cardiac function, specifically in the right ventricle and right atrium. The results for the CG at the beggining of the study were slightly higher than results in the EG. Regarding the inspiratory apnea, an average score of $19 \mathrm{sec}$. was recorded, and an average of $16 \mathrm{sec}$. was recorded in the expiratory apnea. (Table 2). At the end of the study an improvement in both groups was observed, and in the experimental group the two apneic samples were improved on average by $3 \mathrm{sec}$., and apneic samples in the CG were improved on average by $2 \mathrm{sec}$. The results at the end of the study showed a statistically significant increase in time for both inspiration and expiration $(\mathrm{p}<0.01)$.

Oxygen blood saturation at rest is relatively constant, and it is difficult to influence. Changes at the end of the study were insignificant and unreliable. Against the background of stable oxygen saturation, an increase in breathing hold time was observed, which had a direct relationship to the haemodynamics and breathing. We take these small but unidirectional in dynamics results as a consequence of purposefully applied physiotherapy.

The respiratory rate at rest, measured at the beginning and the end of the study, showed significant reductions in both groups, and it was important to take into account that the mean values $(20.8 \pm 1.8)$ in the experimental group were close to the norm (16-20 inspirations/min).

The application of a respiratory training device is an appropriate addition to the PT complex to improve the functional condition of the patients, because it gives positive results, it is safe, easy, and convenient to use, and it does not require continuous control by a physiotherapist.

\section{Conclusion}

In conclusion, the present study shows that the use of a non-resistance inducer device in COPD patients at the clinical stage is appropriate and has a positive effect on oxygen saturation, respiratory muscular strength, and respiratory rate at rest.

\section{Reference}

Berry, M., Rejeski, W., Adair, N., et al. (1999), Exercise rehabilitation and chronic obstructive pulmonary disease stage, Am J Respir Crit Care Med, Vol.160, pp. 1248-53

Dimitrova, A. (2013), Geriatrichna dikhatelna rekhabilitatsiya, Betaprint - Petrovi i Sie, Sofiya

Dimitrova, A. (2009), Pulmonalna rekhabilitatsiya pri khronichna dikhatelna nedostatŭchnost i khronichna obstruktivna belodrobna bolest, In Spiro, Vol. 2, pp. 24-29

Foglio, K., Bianchi, L., Bruletti, G., et al. (1999), Longterm effectiveness of pulmonary rehabilitation in patients with chronic airway obstruction, Eur Respir J, Vol.13, pp. 125-132

Global Initiave for Chronic Obstructive Pulmonary Disease (GOLD), (2014), Global strategy for the diagnosis, management and prevention of chronic obstructive pulmonary disease

Gosselink, R. (2011), Controlled breathing and dyspnea in patients with chronic obstructive pulmonary disease, J Rehabil Res Dev, Vol.40, pp. 25-34

Griffiths, T., Burr, M., Campbell, I., et al. (2000), Results at 1 year of outpatient multidisciplinary pulmonary rehabilitation: a randomised controlled trial, Lancet, Vol. 355, pp. 362-368

Karaneshev, G. (1991), Obshta teoriya i metodika na lechebnata fizkultura, Meditsina i fizkultura, Sofiya

Kostov, K. (2004), KHOBB. Ima li takava bolest?, Monografiya, Ankos, Sofiya

10. Slŭnchev, P., Bonev, L., Bankov, S. (1986), Rŭkovodstvo po kineziterapiya., Î́ izdanie, Meditsina i fizkultura, Sofiya

Slŭnchev, P., Toteva, M. (1975), Rŭkovodstvo za prakticheski uprazhneniya po meditsinski nadzor, Meditsina i fizkultura, Sofiya

Young, P., Dewse, M., Fergusson, W., et al. (1999), Improvements in outcomes for chronic obstructive pulmonary disease (COPD) attributable to a hospital - based respiratory rehabil-itation programme, Aust N Z J Med, Vol. 29, pp. 59-65

Correspondence address:

Assistant Profesor Milena Nikolova, Ph. D.

Department of Physiotherapy and Rehabilitation

National Sports Academy "Vassil Levski", Sofia, Bulgaria

Gurgulyat str. 1, 1000 Sofia, Bulgaria

Mobile: +359897883358

E-mail address: milenanikolova78@gmail.com 